Geochemical Journal, Vol. 1, pp. 51 to $54,1967$.

\title{
Isotopic composition of magnesium in upper mantle materials and a meteorite
}

\author{
Noburu Takematsu ${ }^{1 *}$, Sadao Matsuo ${ }^{1}$, and Shinji Sato ${ }^{2}$ \\ Department of Chemistry ${ }^{1}$, and Department of Geology ${ }^{2}$, \\ Tokyo Kyoiku University, Otsuka, Tokyo, Japan
}

(Received November 1, 1966)

\begin{abstract}
The isotopic ratios of magnesium in rocks coming from the upper mantle and Bruderheim chondrite were measured by a solid-source mass spectrometer.

There is no significant difference in ${ }^{25} \mathrm{Mg} /{ }^{24} \mathrm{Mg}$ and ${ }^{26} \mathrm{Mg} /{ }^{24} \mathrm{Mg}$ between materials constituting the mantle and Bruderheim chondrite within the limits of $95 \%$ confidence. The standard errors of both ${ }^{25} \mathrm{Mg} /{ }^{24} \mathrm{Mg}$ and ${ }^{26} \mathrm{Mg} /{ }^{24} \mathrm{Mg}$ measurements of a sample were about $0.5 \%$.
\end{abstract}

\section{INTRODUCTION}

Magnesium is one of the major constituents of the earth's mantle and stony meteorites. It is of interest to see if there is any difference in the isotopic ratios of magnesium between materials of the earth's mantle and meteorites. It is also interesting to find out if there is any change in the ratios of magnesium isotopes among cogenetic magnesium bearing minerals in a rock or if there is any fractionation of magnesium isotopes during the crystallization of a magmatic melt. Recently several papers have been published on the isotopic ratios of magnesium in materials of geochemical interest. Daughtry et al. (1962), and Sutinov and Artemov (1965) measured ${ }^{24} \mathrm{Mg} /{ }^{26} \mathrm{Mg}$ ratio in dolomites. Kirillov et al. (1963) observed ${ }^{25} \mathrm{Mg} /{ }^{24} \mathrm{Mg}$ and ${ }^{26} \mathrm{Mg} /{ }^{24} \mathrm{Mg}$ in natural carbonates, SHim (1964) in the standard samples of rocks G 1 and W-1, seawater and reagent magnesium, Buchs et al. (1965) in 22 samples of minerals and rocks, and CATANZARo et al. (1966) in 60 natural samples, including carbonate, evaporite, hydroxide, silicate, oxide, seawater, brine, meteorite and biological samples. Daughtry et al. and Kirillov et al. reported variations in different geological enviroments, while other researchers found no appreciable variation. In this study, the isotopic ratios of magnesium in coexisting silicate minerals in dunite, periodtite and a meteorite were measured.

\section{SAMPLES}

Dunite which is supposed to be a fresh sample coming from the upper mantle

* Present address: The Institute of Physical and Chemical Research, Honkomagome, Tokyo, Japan. 
(S. IrzumI, private communication) was collected at Ōgawara, Nagano Prefecture, Japan. Olivine was separated from the dunite and subjected to isotopic ratio measurement. Serpentinite associated with the dunite was taken as a sample. According to field observation, the serpentinite was originated from dunite through metamorphism (Shimazu, 1956). The isotopic ratios of magnesium in enstatite and diopside in a peridotite collected at Horoman, Hokkaido, Japan, which, according to ONUKI (1965), is characterized by the high temperature liquid intrusion, were also analyzed. Bruderheim chondrite which was given by Prof. Honda of The Institute for Solid State Physics at Tokyo University was also analyzed. After crashing pieces of rock samples into powder of 200-250 mesh, minerals were separated by an isodynamic separator. By the microscopic examination, the purity of separated minerals was estimated to be more than $95 \%$.

\section{EXPERIMENT AND RESULT}

After decomposing a silicate sample by digestion with hydrofluoric acid and dilute sulfuric acid, bromine water was added to the solution in order to oxidize ferrous ion. After separating iron and aluminum as hydroxides, and calcium as oxalate, magnesium was precipitated by ammonium dihydrogen phosphate. The further purification was carried out following the method by Yoshimura et al. (1957). The precipitate of magnesium was dissolved in conc. hydrochloric acid and the solution was passed through Dowex 1-X 8 anion exchange resin to eliminate manganese. Then, sodium and aluminum which give adjacent mass spectra to those of magnesium were separated by Dowex $50-\mathrm{X} 8$ cation exchange resin. The fraction of effluent containing magnesium was evaporated to dryness. The residue was converted to magnesium nitrate by nitric acid, and finally the nitrate was ignited to magnesium oxide.

Isotopic measurement was made with a Hitachi RMU-6 A solid-source mass spectrometer with a $20 \mathrm{~cm}$ radius of curvature and a deflection of $90^{\circ}$. An ion source with double-filament of rhenium ribbon $(0.001 \times 0.030$ inches $)$ was used. Ion current of magnesium was measured by a vibrating reed electrometer which detects $10^{-15} \mathrm{~A}$. The ratios were measured by magnetic scanning at a constant ion-accelerating voltage of $2 \mathrm{kV}$. In measuring the isotopic ratios of magnesium, the filament must be free from alkaline metals, especially from sodium. Therefore, the rhenium ribbon was pre-heated in a vacuum for an hour to minimize the contamination with sodium. About $100 \mu \mathrm{g}$ of magnesium oxide was loaded on the sample filament with phosphoric acid (ShrmA, 1964), and dried up by an infrared lamp, passing an electric current through the filament. After loading the ion source and evacuating the system, the electric current of the ionization filament was gradually increased until the ion current of ${ }^{187} \operatorname{Re}$ reached the extent of $10^{-12}$ A. Then, the current through the sample filament was slowly increased up to $2 \mathrm{~A}$ and let to stand overnight to expel sodium. After the ion current of ${ }^{23} \mathrm{Na}$ decreased 
to below $10^{-13} \mathrm{~A}$, the electric current through the sample filament was gradually increased again until the ion current of ${ }^{24} \mathrm{Mg}$ reached the range of $5 \times 10^{-13} \mathrm{~A}$ to $1 \times 10^{-12} \mathrm{~A}$. It took about 20 hours from the beginning for the ion current of magnesium to become stable enough for measurement. Scanning was repeated 20-35 times. Samples containing much sodium gave only weak and unstable ion current of magnesium. The normal run gave an increasing current in the beginning, constant current in the middle stage and in the final stage the ion current decreased linearly with time. The isotopic ratios which were obtained at the last stage of decreasing ion-current gave the smallest standard errors, however. a strong mass fractionation was suspected. Thus, in this study the isotopic ratios were determined using the observed values at the middle stage where the ion current was constant.

An example of mass spectra is shown in Fig. 1. The peak heights of ${ }^{25} \mathrm{Mg}$ and ${ }^{26} \mathrm{Mg}$ are enlarged by about $10 / 3$ times relative to that of ${ }^{24} \mathrm{Mg}$. The observed iso-

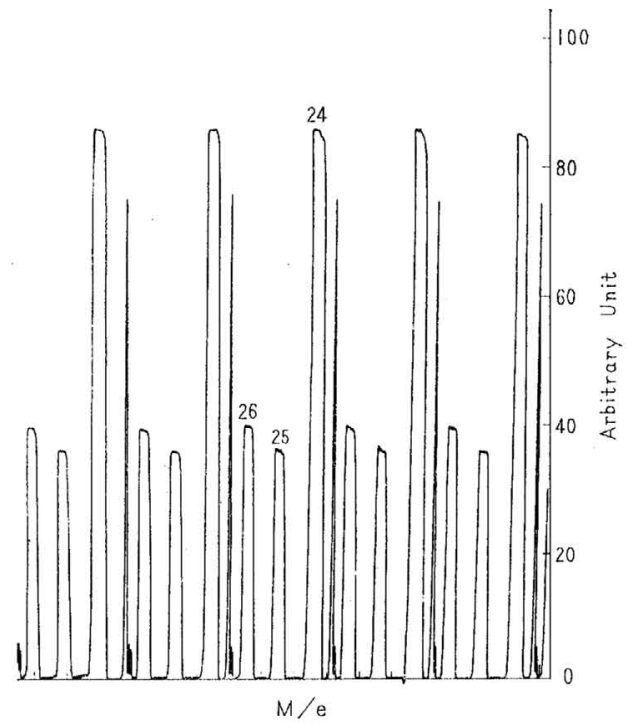

Fig. 1. An example of the mass spectra of magnesium isotopes

Table 1. Observed ${ }^{25} \mathrm{Mg} /{ }^{24} \mathrm{Mg}$ and ${ }^{26} \mathrm{Mg} /{ }^{24} \mathrm{Mg}$ in the samples

\begin{tabular}{llcc}
\hline \multicolumn{1}{c}{ Rock samples } & $\begin{array}{c}\text { Minerals } \\
\text { separated }\end{array}$ & \multicolumn{2}{c}{ Isotopic ratios } \\
& ${ }^{25} \mathrm{Mg} /{ }^{24} \mathrm{Mg}$ & ${ }^{26} \mathrm{Mg} /{ }^{24} \mathrm{Mg}$ \\
\hline Dunite (Ōgawara) & Olivine & $0.1259 \pm 0.0005$ & $0.1397 \pm 0.0005$ \\
Serpentinite (Őgawara) & Bulk & $0.1261 \pm 0.0008$ & $0.1389 \pm 0.0006$ \\
Peridotite (Horoman) & Enstatite & $0.1259 \pm 0.0005$ & $0.1386 \pm 0.0008$ \\
& Diopside & $0.1265 \pm 0.0006$ & $0.1386 \pm 0.0005$ \\
Chondrite (Bruderheim) & Bulk & $0.1266 \pm 0.0011$ & $0.1400 \pm 0.0012$ \\
\hline
\end{tabular}


topic ratios without the correction for the mass discrimination are listed in Table 1. The isotopic ratios of enstatite in Horoman peridotite were measured twice and the results agreed well within the limit of standard errors of each run. As seen in Table 1, the standard errors of both ${ }^{25} \mathrm{Mg} /{ }^{24} \mathrm{Mg}$ and ${ }^{26} \mathrm{Mg} /{ }^{24} \mathrm{Mg}$ measurements of a sample are about $0.5 \%$. Assuming that the maximum standard errors obtained so far in this study, i.e. $0.87 \%$ for ${ }^{25} \mathrm{Mg} /{ }^{24} \mathrm{Mg}$ and $0.86 \%$ for ${ }^{26} \mathrm{Mg} /{ }^{24} \mathrm{Mg}$ represent the standard errors of the population in the statistics, the range of ${ }^{25} \mathrm{Mg} /{ }^{24} \mathrm{Mg}$ and ${ }^{26} \mathrm{Mg} /{ }^{24} \mathrm{Mg}$ are estimated to be $0.1252-0.1270$ and $0.1380-0.1400$ respectively under $95 \%$ confidence limit. All the isotopic ratios observed in this study fall in the above ranges. In other words, there seems no significant difference in ${ }^{25} \mathrm{Mg} /{ }^{24} \mathrm{Mg}$ and ${ }^{26} \mathrm{Mg} /{ }^{24} \mathrm{Mg}$ ratios between materials constituting the mantle and the meteorite, and between coexisting magnesium bearing minerals in a rock.

\section{Acknowledgements}

The authors are grateful to Prof. Y. Miyake of Tokyo Kyoiku University for his encouragement throughout the study. We wish to thank Dr. E. J. Catanzaro of National Bureau of Standards, U.S.A., who gave us rhenium ribbons and much valuable information. We are indebted to Messrs. S. Iizumi and M. Suzuki for collaboration during sample collection.

\section{REFERENCES}

BUCHS, A., KRUMMENNACHeR, D. and Noetzlin, J. (1965) The isotopic composition of magnesium extracted from rocks and lavas of very different origins. Schweiz. Mineral. Petro. Mitt. 45, 847-853.

CATANZARo, E. J. and MURPhy, T. J. (1966) Magnesium isotope ratios in natural samples. J. Geophys. Res, 71, 1271-1274.

Daughtry, A. C., Perry, D. and Williams, M. (1962) Magnesium isotopic distribution in dolomite. Geochim. Cosmochim. Acta 26, 857-866.

KIRILLOV, A. S. and RYLOV, V. S. (1963) Origin of magnesium in carbonatites. Zap. Vses. Mineralog. Obshchestva 92, 228-231 (in Russian).

ONUKI, H. (1965). Petrochemical research on the Horoman and Miyamori ultramafic intrusives, northern Japan. Science Reports of the Tohoku Univ. 3rd series 9, 217-276.

ShimA, M. (1964) The isotopic composition of magnesium in terrestrial samples. Bull. Chem. Soc. Japan 37, 284-285.

ShimazU, M. (1956) Ultramafic and mafic rocks of Shimo-Ina District, Nagano Prefecture. J. Jap. Ass. Min. Petr. Econ. Geol. 40, 207-216.

Sutinov, V. I. and ARTEMOv, Y. M. (1965) Mass-spectrometric determination of isotopic composition of magnesium. Geochemistry 2, 476-478.

YOSHIMURA, J. and WAKI, H. (1957) Analytical method for silicates using ion-exchange resins. Japan Analyst 6, 362-369 (in Japanese with English abstract). 